\title{
UNIVERSITY CITIES AND THEIR ROLE IN THE SPATIAL DISTRIBUTION OF CREATIVE ECONOMIES
}

DOI: http://dx.doi.org/10.18509/GBP.2019.32

UDC: $330.34: 378.091 .6(498)$

\author{
Marian Marin ${ }^{1,2}$ \\ Radu-Daniel Pintilii ${ }^{1,2}$ \\ Andreea Karina Gruia ${ }^{1,2}$ \\ Daniel Peptenatu ${ }^{1,2}$ \\ Alexandra Grecu ${ }^{1,2}$ \\ ${ }^{1}$ University of Bucharest, Faculty of Geography, Romania \\ ${ }^{2}$ University of Bucharest, Research Center for Integrated Analysis \\ and Territorial Management (CAIMT), Romania
}

\begin{abstract}
Disparities in the distribution of creative industries seems to be today a relevant indicator for identifying syncopes development of a territory. The study aims to highlight the role of university centers in Romania in the distribution of creative industries, how the importance of university centers contributes to the shaping of certain spatial patterns of distribution and development. The link between innovation and the results of creative activities at local and regional level was also analyzed. Research it's started from a fourdigit CAEN (National Economy Activities Clasification) code database for the 2000-2016 period, which included, for the activities specific to the creative economies, the following indicators: the evolution of the number of firms, the turnover dynamics, the profit evolution, the evolution of the number of employees. The database was developed for all 3181 administrative units in Romania, which allowed for a very good contextualization for the 27 university centers. In the development of this study, the QGIS platform was used to map cartographic materials, and RSoftware (R5.5.1) was used for correlational analysis of the variables. The spatial design of the creative economies, at this level of analysis, has enabled the identification of the university cities determinant role in concentrating the creative economies and shaping clusters around the main university centers in Romania, a phenomenon whose intensity differs according to the size of the university center.
\end{abstract}

Keywords: territorial systems, development engine, creative universities, smart cities, intelligent territorial development

\section{INTRODUCTION}

Given that the creative industries are contributing to the current economic growth, it is extremely important to identify the activities, included in this category. According to Florida's classification [1], creative activities are gathered into two categories: the "supercreative kernel" and "creative professionals." The core is the one that generates products and ideas while professionals aim to apply knowledge and solve problems. From this perspective, university cities play an extremely important role, at least if we refer to the production of (scientific) ideas.

At European level, around $67 \%$ of the population live in medium-sized towns (less than 500,000 inhabitants) while $9.6 \%$ are in cities with more than 5,000,000 inhabitants. 
Europe is otherwise characterized by a polycentric rather than concentrated urban structure compared to the US or China. Examples are Hungary, Lithuania, Slovakia, where we are talking about a single metropolitan area, so we can say that the size of the population is an important indicator of the economy and urban development [2].

Urban development is a dynamic process that is influenced by different physical and socio-economic factors $[3,4,5,6]$. So, important changes in land use can have socioecological consequences, determined by different constraints [7, 8].

The evolution of the creative sector in recent years has generated a new approach to land use and market value. It is all due to the interaction between ecosystems and cultural groups through technologies and institutions $[9,10,11,12,13]$. Thus, complex centers have developed within the university centers, which have led to a particular approach in terms of employment, changes in the environment and the economy - relations with the outside.

Recently, as regards the situation in Romania, the role played by the university centers of tradition, namely that of development poles, centers of coagulation of creative activities, is highlighted.

\section{MATERIAL AND METHODS}

For the analysis of the creative field, the biggest five universities of Romania, were considered. They touch the criterion of being located in cities with a population of more than 300,000 inhabitants: Bucharest, Cluj-Napoca, Iași, Timișoara and Constanța (Figure 1). Except Bucharest, which has the status of capital of Romania, the others have the state of residence of the county, thus bringing into question a strong administrative background. If we relate to their size, they are large cities, which coagulate both labor force and financial flows within the territorial units.

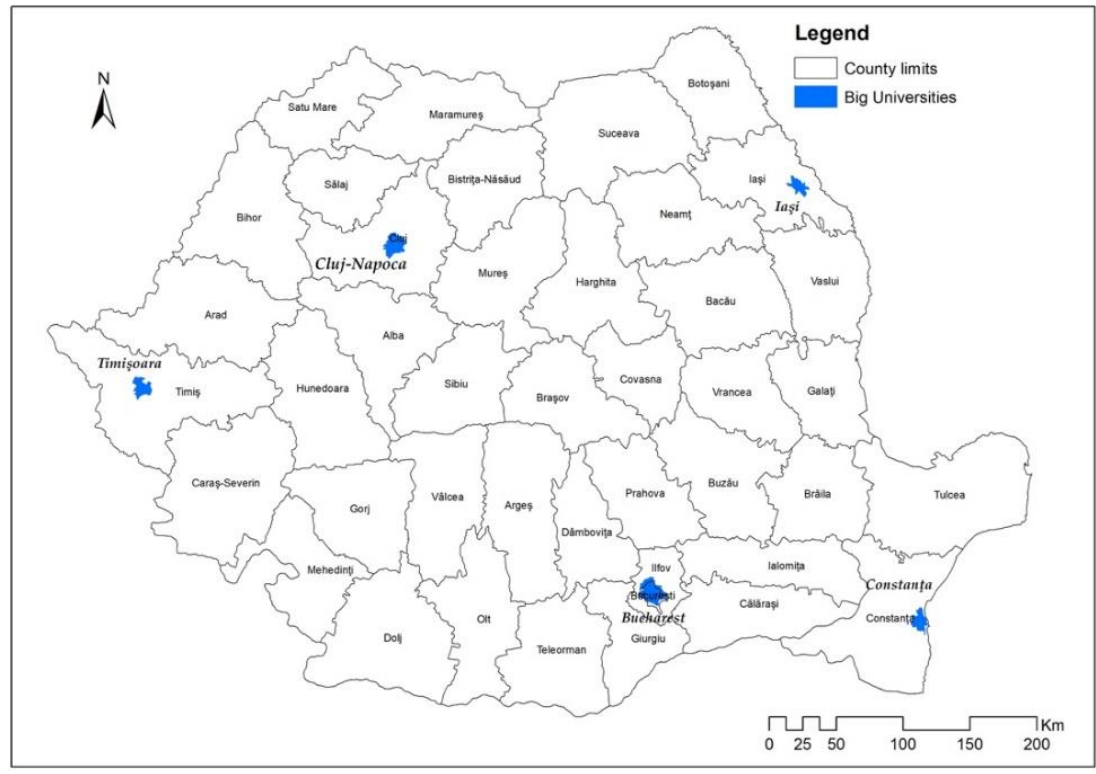

Figure 1. Geographical position of the five universities

To obtain the necessary data on creative economies, multiple sources have been chosen number of companies, employees, profits and turnover figures. These were extracted from the database of the Center for Integrated Analysis and Territorial Management, carried out under the UB/1365 Project. The NACE codes were used to classify the creative activities, and the school population was taken over through the Tempo Online platform. 
The cartographic materials, showing the territorial distribution of the universities in Romania were made using the QGIS platform, and the correlation graphs of the ranks (Kendall's coefficient $\mathrm{t} b$ ), between the creative and share of students, were made under RSoftware (R 5.5.1 - open source). The correlation highlighted by the coefficient size (values between -1 and +1 ).

\section{RESULTS}

In Figure 2, a curious situation is registered for Bucharest (Figure 2a), the Capital city of Romania, the biggest city, with over 1 million inhabitants. This is the most important city of the country and here can be found the most important universities, in branches, from whole country. The lack of the correlation is due to the value of the standard deviation, that is equal to zero. The explanation of the situation comes from the fact that here, there is a very large palette of specialties the universities are having. Not only the creative ones but also other fields are located here.
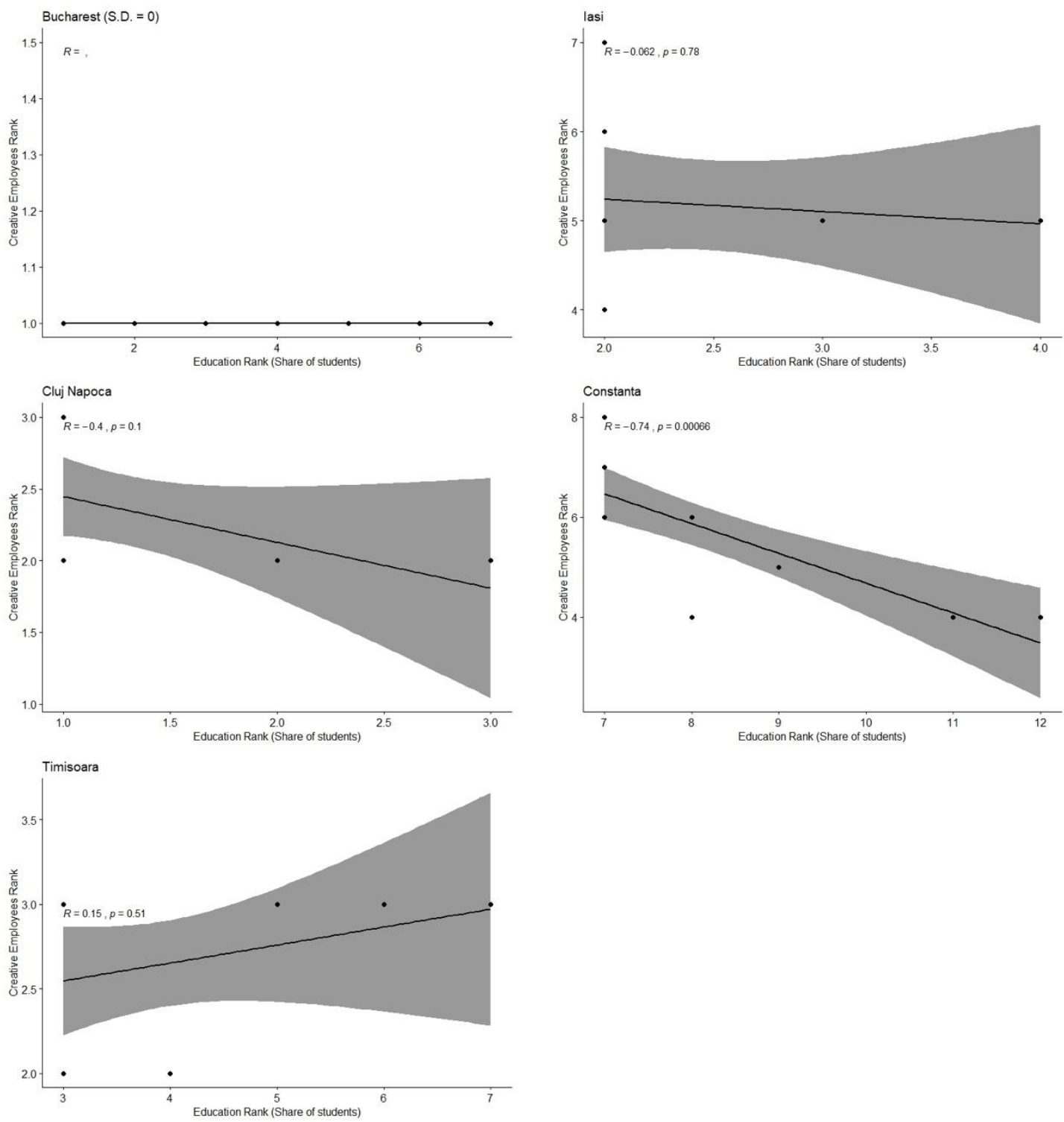

Figure 2. (a-e) Kendall correlation coefficient for the five biggest universities in Romania 
Other big cities, with big universities register negative or positive correlations of Kendall index. The same Figure 2 illustrates strong negative correlations for Iași (with $R$ value 0,062 and a $p$ value 0,78), Cluj-Napoca (with $R$ value $-0,4$ and a $p$ value 0,1 ) and Constanța (with $R$ value $-0,74$ and a $p$ value 0,00066 ), due to the same large spread of the specialties in the territory. The single one, of the five university cities, chosen as a case study, is Timișoara (with $R$ value 0,15 and a $p$ value 0,051 ), where a weak, but positive correlation can be met (Figure 2e). All the strong and the weak correlations are explained by the values of $R$ and $p$ values.

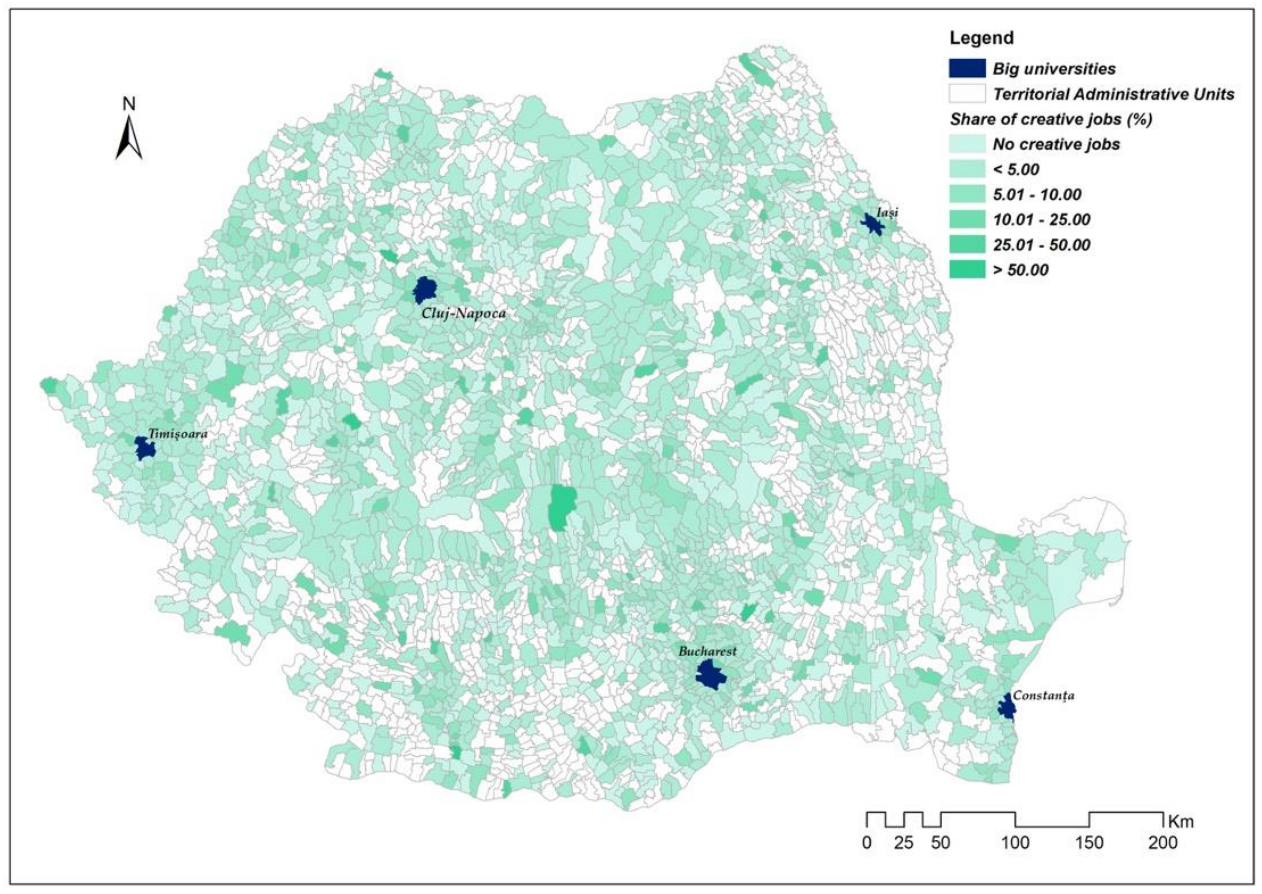

Figure 3. Territorial distribution of the creative jobs in Romania

In Figure 3, it can be seen that in the territorial profile, the big universities develop a strong capacity of structuring creative activities around. The localizing of the creative activities is correlated with the economic and demographic power of every university city. Every city of the five has an important university activity so that they could act as a real incubator for such kind of economy.

\section{CONCLUSIONS AND DISCUSSION}

In the last three decades, after the fall of the communist regime in Romania, the creative economic activities have a prosperous evolution, but with an unequal measure $[14,15]$. The hegemony of the Capital city and its urban influence area can be observed, due to its offer in terms of development, for this kind of activities. It is about space, infrastructure, labor force, economic and social conditions [16, 17].

The importance of the creative economies in the development of the local economies results from their capacity of acting as real engines, especially in the structural crisis periods. They can be seen as some substitute economic activities to help some territorial systems to pass over the crisis period [18].

An important key factor for the economic development is played by the research development and innovation field. It plays an important role in order to start an inner migration of the labor force and only the university could do that. 


\section{REFERENCES}

[1] Florida R. The rise of the creative class, The Washington Monthly, vol. 34, pp 15-25, 2002a.

[2] Kumar T. M. V. \& Dahiya B. Smart economy in smart cities, Springer Nature: Singapore, 2016.

[3] Akın A., Clarke K. C. \& Berberoglu The impact of historical exclusion on the calibration of the SLEUTH urban growth model, International Journal of Applied Earth Observation and Geoinformation, vol. 27, pp 156-168, 2014.

[4] Irwin E. G., Jayaprakash C., \& Munroe D. K. Towards a comprehensive framework for modeling urban spatial dynamics, Landscape Ecology, vol. 24, pp 1223-1236, 2009.

[5] Maimaitijiang M., Ghulam A., Sandoval J. O. \& Maimaitiyiming, M. Drivers of land cover and land use changes in St. Louis metropolitan area over the past 40 years characterized by remote sensing and census population data, International Journal of Applied Earth Observation and Geoinformation, vol. 35, pp 161-174, 2015.

[6] Shafizadeh-Moghadam H. \& Helbich M. Spatiotemporal variability of urban growth factors: A global and local perspective on the megacity of Mumbai, International Journal of Applied Earth Observation and Geoinformation, vol. 35, pp 187-198, 2015.

[7] Liu X., Li X. \& Shi X. Simulating complex urban development using kernelbased non-linear cellular automata, Ecological Modelling, vol. 211, pp 169-181, 2008.

[8] Yang X. \& Lo C. P. Modeling urban growth and landscape changes in the Atlanta metropolitan area, International Journal of Geographical Information Science, vol. 17, pp 463-488, 2003.

[9] Bowler J. M., Johnston H., Olley J. M., Prescott J. R., Roberts R. G., Shawcross W., \& Spooner N. A. New ages for human occupation and climatic change at Lake Mungo, Australia. Nature, vol. 421(6925), pp 837-840, 2003.

[10] Pinto-Correia, T. \& Kristensen, L. Linking research to practice: The landscape as the basis for integrating social and ecological perspectives of the rural, Landscape and Urban Planning, vol. 120, 248-256, 2013.

[11] Taylor R. B. Human territorial functioning: An empirical, evolutionary perspective on individual and small group territorial cognitions, behaviors, and consequences, Cambridge, New York, New Rochelle, Melbourne, Sydney: Cambridge University Press, 1988.

[12] Silveira P. \& Ponce Dentinho T. A spatial interaction model with land use and land value, Cities, vol. 78, pp 60-66, 2018.

[13] Borsekovaa K., Korónya S., Vaňováb A. \& Vitálišová K. Functionality between the size and indicators of smart cities: A research challenge with policy implications, Cities vol. 78, pp 17-26, 2018.

[14] Stoian D., Peptenatu D., Pintilii R. D. \& Schvab A. Territorial Distribution of Creative Poles in Romania, Procedia Social and Behavioral Sciences, vol. 122, pp 184-188, 2014.

[15] Pintilii R. D., Braghina C., Draghici C. C. \& Saghin I. Territorial imbalances in the distribution of the creative industries in the North-Eastern Development Region, Procedia Social and Behavioral Sciences, vol. 122, pp 179-183, 2014.

[16] Peptenatu D., Draghici C. \& Merciu C. Characteristics of entrepreneurial profile in some emergent territorial structures in Romania, Actual problems of economics, vol. 138, pp 448-458, 2012.

[17] Pintilii R. D., Peptenatu D., Ciobotaru A. M., Toma S. G., Grigore A. M., Drăghici C. C., Dobrea R. C., Simion A. G., Andronache I., Teodorescu C. \& Diaconu C. D. Creative economies in Romania - spatial projections and trends, Bulletin of Geography. Socio-economic Series, vol. 37, pp 95-108, 2017. 
[18] Peptenatu D., Merciu C., Merciu G., Drăghici C. \& Cercleux L. Specific features of environment risk management in emerging territorial structures, Carpathian Journal of Earth and Environmental Sciences, vol. 7, pp 135-143, 2012. 